\title{
ANALISIS FAKTOR YANG MEMPENGARUHI PENGGUNAAN APLIKASI FINTECH DAN DAMPAKNYA TERHADAP LITERASI KEUANGAN
}

\author{
Oktavia Marpaung ${ }^{1}$, Darwin Marasi Purba ${ }^{2}$, Siti Maesaroh ${ }^{3}$ \\ ${ }^{1}$ Sekolah Tinggi Ilmu Ekonomi Jayakarta; Oktavia.jykt@gmail.com \\ ${ }^{2}$ Universitas Binaniaga Indonesia; Mazmur.911516@gmail.com \\ ${ }^{3}$ Sekolah Tinggi Ilmu Ekonomi Insan Pembangunan; siti.maesaroh1988@gmail.com
}

\begin{abstract}
ABSTRAK
Teknologi keuangan atau Financial technology (fintech) dalam perkembangannya yang semakin luas akan berdampak terhadap perilaku penggunaan fintech. Perilaku penggunaan fintech mencoba menjelaskan dan mengetahui tentang jumlah masyarakat yang menggunakan atau tidak menggunakan teknologi fintech serta pemahaman masyarakat tentang pola pengembangan dan sejauh mana cara penggunaan fintech dikenal baik dari fitur serta manfaat dan kenyamannya. Penelitian ini bertujuan untuk mengetahui faktor yang mempengaruhi perilaku penggunaan aplikasi Financial technology (fintech) dan dampaknya terhadap literasi keuangan khususnya di Provinsi Daerah Khusus Ibu Kota Jakarta. Metode penelitian menggunakan metode penelitian analisis deskriptif kualitatif. Teknik dari penentuan sampel dengan menggunakan metode purposive sampling. Hasil penelitian adalah bahwa beberapa faktor yang dapat mempengaruhi penggunaan fintech dari sisi pengguna adalah usia, jenis kelamin, pekerjaan, pendapatan, tingkat pendidikan pengguna fintech sedangkan dari sisi aplikasi fintech adalah perkembangan teknologi dari aplikasi fintech, minat konsumen dari fitur dan produk yang ditawarkan oleh aplikasi fintech serta kenyamanan pengguna dalam menggunakan aplikasi fintech tersebut. Dan dalam inklusi keuangan dampaknya dapat meningkatkan literasi keuangan khususnya masyarakat yang ada di DKI Jakarta yang digunakan sebagai responden. Penggunaan aplikasi fintech banyak digunakan oleh generasi milenial yang memberikan kemudahan-kemudahan dan kenyamanan dalam mengakses berbagai jenis layanan keuangan yang ada. Penggunaan layanan Financial technology oleh para pengguna smartphone atau ponsel pintar dapat menjadi jawaban atas upaya pemerintah membangun kebiasaan less-cash society serta upaya dalam meningkatkan literasi keuangan masyarakat Indonesia. Sebab jumlah pengguna handphone terlebih ponsel pintar di Indonesia sudah sangat banyak. Penetrasi smartphone atau ponsel pintar di Indonesia sudah melebihi penetrasi akun bank di Indonesia.
\end{abstract}

Kata Kunci: Financial Techonology, Literasi Keuangan.

\begin{abstract}
The Financial technology (fintech) in its development is getting wider, it will have an impact on the behavior of using fintech. The behavior of using fintech tries to explain and find out about the number of people who use or don't use fintech technology as well as people's understanding of development patterns and the extent to which how to use fintech is known both from its features and benefits and comfort. The purpose of this study is to determine the factors that influence the behavior of using Financial technology (fintech) applications and their impact on financial literacy, especially in the Special Capital District of Jakarta. The study method used is a qualitative descriptive analysis method.. The technique of determining the sample using purposive sampling method. The result of this study is that some of the factors that can influence the use of fintech from the user point of view are age, gender, occupation, income, education level of fintech users, while in terms of fintech applications are the technological developments of the fintech application, consumer interest from the features and products offered by the fintech application and the convenience of users in using the fintech application. And in financial inclusion, the impact can increase financial literacy, especially people in DKI Jakarta who are used as respondents. It can be seen that many millennial generations use fintech applications so that they can provide convenience and comfort in accessing various types of financial services that exist. The use of
\end{abstract}


Financial technology services by smartphone can be an answer to the government's efforts to build a cashless society and efforts to improve financial literacy in Indonesians. Because the number of cellphone users, especially smart phones in Indonesia, is already very large. "The penetration of smartphones in Indonesia has already exceeded the penetration of bank accounts in Indonesia."

Keywords: Financial Techonology, Financial Literacy.

Naskah diterima : 12-04-2021, Naskah dipublikasikan : 30-04-2021

\section{PENDAHULUAN}

Berdasarkan survey yang dilakukan oleh Otoritas Jasa Keuangan (OJK) untuk tahun 2019 bahwa literasi keuangan hanya mencapai indeks $38,03 \%$ yang dimana telah meningkat dibandingkan dengan survei tahun 2016 yang hanya mencapai $29.7 \%$ namun jika dibandingkan dengan indeks inklusi keuangan $76.19 \%$ yang mana akan dapat berdampak buruk bagi kehidupan masa kini dan masa depan bagi individu masyakat Indonesia secara khusus dan perekonomian bangsa secara umum.

Perkembangan yang pesat dari teknologi dan komunikasi pada saat ini menyebabkan perubahan dalam kehidupan manusia baik di bidang sosial, ekonomi, kesehatan, pendidikan, transportasi, dan lainlain. Teknologi sudah menjadi bagian yang tidak lagi dipisahkan dalam kehidupan sehari-hari. Seiring dengan semakin tingginya aktivitas manusia, dibutuhkan sesuatu alat bantu yang praktis agar memberikan kemudahan-kemudahan dan kenyamanan manusia dalam melakukan berbagai aktivitas sehari-hari. Teknologi sangatlah memegang peranan yang penting dalam menunjang kemudahankemudahan dan kenyamanan tersebut yang salah satunya adalah dengan teknologi informasi. Perkembangan teknologi informasi memberikan dampak yang berarti dan signifikan pada berbagai lapisan kehidupan masyarakat, baik untuk individu maupun organisasi dalam pemanfaatan sumber daya sehingga menjadi lebih mudah dan efisien. Semakin berkembangnya teknologi informasi membuat semakin pentingnya hal tersebut didalam kehidupan.

Teknologi informasi yang ada pada segmen teknologi keuangan atau Financial technology (fintech) dalam perkembangannya akan berdampak terhadap perilaku pengguna fintech. Perilaku pengguna fintech mencoba menjelaskan dan mengetahui tentang jumlah masyarakat yang menggunakan atau tidak teknologi fintech, pemahaman masyarakat tentang pola pengembangan dan sejauh mana cara penggunaan fintech dikenal baik dari fitur serta manfaatnya. Sehingga secara lebih spesifik perilaku pengguna fintech digunakan dalam memahami isu-isu dan tingkah laku yang berkaitan dengan perilaku pengguna fintech dari setiap individu.

Penelitian ini bertujuan untuk mengetahui dan menjawab faktor - faktor apa saja yang dapat mempengaruhi perilaku penggunaan aplikasi Financial technology (fintech) dan Apa dampaknya terhadap literasi keuangan khususnya di Provinsi Daerah Khusus Ibu Kota Jakarta.

\section{KAJIAN LITERATUR}

Menurut Costa dan Grauwe dalam (Fatmawati \& Yuliana, 2019) menyebutkan dengan adanya penggunaan dari alat-alat pembayaran yang tidak menggunakan uang tunai atau yang lebih dikenal dengan istilah non tunai secara luas memiliki implikasi pada berkurangnya permintaan terhadap uang yang diterbitkan oleh bank sentral, base money yang pada dasarnya dapat mempengaruhi pelaksanaan tugas bank sentral dalam melaksanakan kebijakan-kebijakan moneter khususnya pengendalian dari besaran moneter. Sedangkan menurut Freidman dalam (Fauzie \& S Istanto, 2014) adanya perkembangan dari teknologi informasi akan memberikan dampak terkait dengan berkurangnya peran dari base money dalam transaksi pembayaran .

Menurut Herawati et al. (2018) Literasi keuangan merupakan hal yang penting dan tidak bisa dipisahkan dalam proses mengelola keuangan termasuk mengelola keuangan pribadi. Sehingga literasi keuangan dapat diartikan sebagai suatu rangkaian proses atau kegiatan untuk meningkatkan 
pengetahuan (knowledge), keterampilan (skill), dan keyakinan (confidence) dari masyarakat agar mampu mengelola keuangan pribadi dengan lebih baik.

Menurut Otoritas Jasa Keuangan dalam Tiwu (2020) peningkatan dari literasi keuangan sangatlah diperlukan untuk dapat meningkatkan pengetahuan keuangan dalam masyarakat Indonesia. Tetapi penerapan di Indonesia mengenai pembelajaran atau edukasi keuangan kurang berkembang sehingga jarang ditemui baik di lembaga akademik maupun non akademik. Akibatnya literasi keuangan di Indonesia tergolong rendah jika dibandingkan dengan negara-negara tetangga dekat seperti Malaysia dan Thailand. Terbukti pada tahun 2018, hanya sekitar 21,84\% masyarakat Indonesia yang memiliki pemahaman dan pengertian yang baik tentang finansial (Otoritas Jasa Keuangan, 2016).

Dilihat pada hasil penelitian yang dilakukan oleh Muhammad dan Fatimah (2018) menyatakan bahwa literasi keuangan berpengaruh signifikan terhadap penggunaan fintech, kualitas pembelajaran keuangan berpengaruh terhadap penggunaan fintech, literasi keuangan dan kualitas pembelajaran keuangan berpengaruh secara signifikan terhadap penggunaaan fintech.

Menurut Prayustika et al. (2020) Berdasarkan hasil wawancara, semua mahasiswa program studi manajemen bisnis internasional memiliki akun dan menjadi pengguna aktif aplikasi fintech, baik yang merupakan e-commerce ataupun untuk transaksi keuangan online. Aplikasi fintech yang umum digunakan mahasiswa adalah Gopay, OVO, Shopee Pay, Dana.

Hasil penelitian Luh (2019) menemukan bahwa literasi keuangan memiliki pengaruh yang signifikan terhadap financial self-efficacy. Huston (2010) menyatakan bahwa pengetahuan finansial merupakan dimensi yang tidak terpisahkan dari literasi finansial, namun belum dapat menggambarkan literasi finansial.

\section{METODE PENELITIAN}

Adapun metode penelitian yang digunakan yaitu metode penelitian analisis deskriptif kualitatif dengan menganalisis, menggambarkan dan meringkas berbagai kondisi, situasi dari berbagai data yang dikumpulkan berupa hasil wawancara melalui kuesioner yang dibagikan baik langsung maupun tidak langsung. Desain penelitiannya menggunakan penelitian kualitatif studi kasus yang artinya adalah berusaha menemukan makna, menyelidiki proses, dan memperolah pengertian dan pemahaman yang mendalam dari individu, kelompok, atau situasi (Situmorang \& Hapsari, 2019)

Teknik penentuan sampel adalah dengan menggunakan metode purposive sampling. Menurut Sugiyono dalam Situmorang \& Ayustia (2019) purposive sampling merupakan teknik penentuan sampel dengan pertimbangan tertentu. Metode ini digunakan dengan pertimbangan bahwa letak lokasi penelitian yang berpencaran, karakteristik masyarakat yang merupakan dari objek penelitian yang beragam, dan informasi yang diperlukan diperoleh melalui kuesioner yang dibagikan secara online maupun dengan wawancara langsung dan tidak langsung.

\section{HASIL DAN PEMBAHASAN}

Identitas responden dalam tabel berikut ini menunjukkan karakteristik responden berdasarkan kriteria penilaian jenis kelamin, usia, masa kerja, tingkat pendidikan dari responden yang dijadikan sampel dalam penelitian. Penyajian data identitas responden adalah sebagai berikut : 


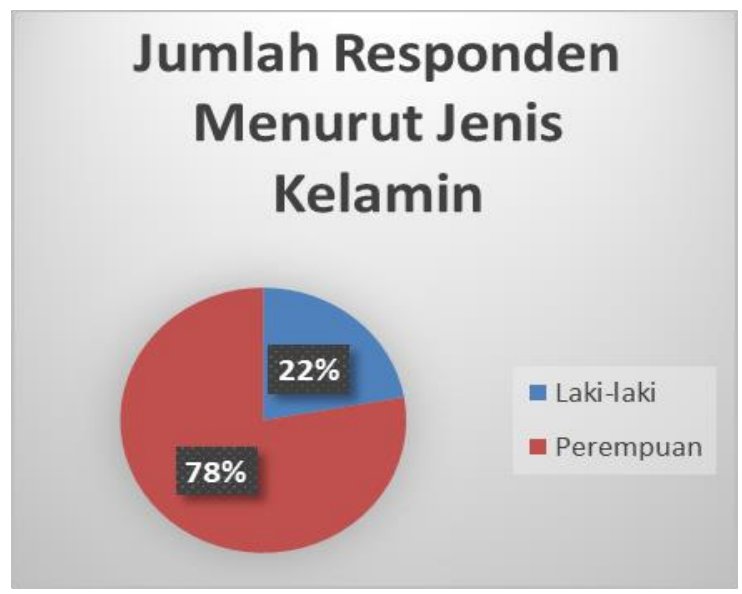

Grafik 1. Responden menurut Jenis Kelamin

Berdasarkan hasil penelitian peneliti menemukan sebanyak 22 responden yang berjenis kelamin Laki-laki dan sebanyak 77 responden yang berjenis kelamin perempuan dengan total semua adalah 99 responden yang dijadikan sebagai objek penelitian ini yakni terdiri dari berbagai daerah atau wilayah yang ada di provinsi DKI Jakarta. Maka dari tabel diatas dapat disimpulkan bahwa yang paling banyak menggunakan finance technology produk Gopay dan Ovo adalah berjenis kelamin perempuan, sehingga perlu peningkatan produk yang berunsurkan produk wanita dalam meningkatkan penggunaan finance teknologi produk Gopay dan Ovo.

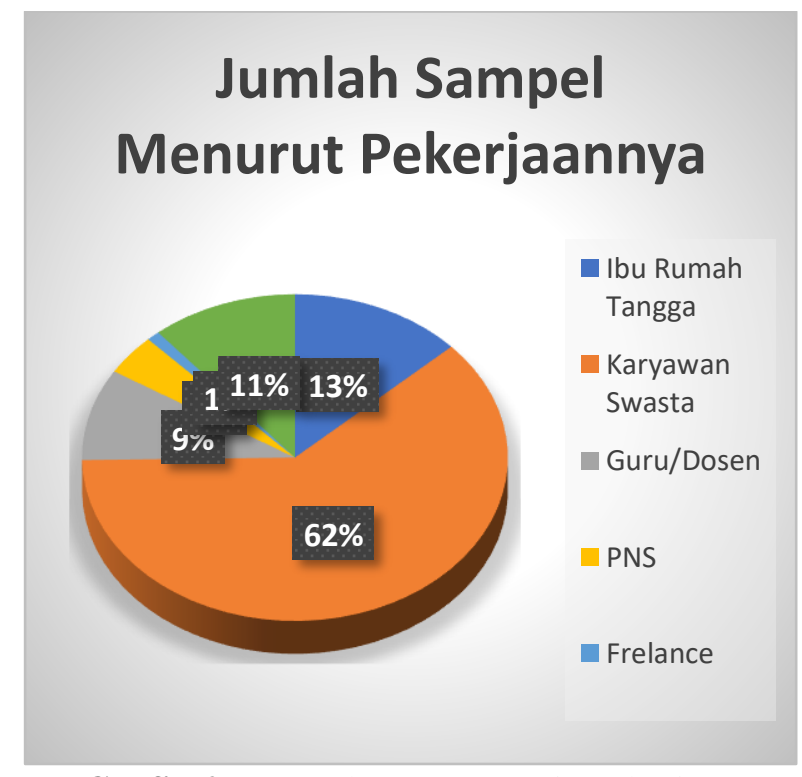

Grafik 2. Sampel menurut Jenis Pekerjaan

Berdasarkan Jumlah Responden dalam penelitian ini, maka jumlah responden yang memiliki status pekerjaan sebagai ibu Rumah Tangga sebanyak 13 responden, kemudian ada sebanyak 61 Responden bekerja sebagai Karyawan Swasta, responden yang memiliki status pekerjaan sebagai Guru/Dosen berjumlah 9 responden, yang bekerja sebagai PNS berjumlah 4 responden, kemudian status pekerjaan sebagai Frelance sebanyak 1 responden dan pekerja Wiraswasta sebanyak 11 responden. Dari hasil di atas maka disimpulkan bahwa potensi untuk meningkatkan penggunaan finance teknology dapat dikembang dari segmen pengguna yang berprofesi sebagai karyawan. 


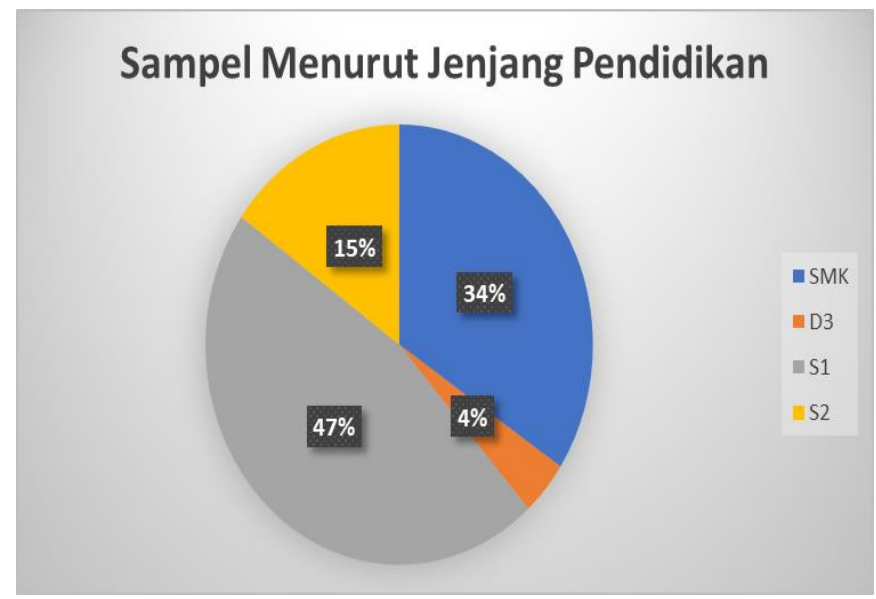

Grafik 3. Sampel menurut Jenjang Pendidikan

Dari hasil penelitian jumlah responden yang memiliki jenjang Pendidikan SMK sebanyak 34 responden, jenjang Pendidikan D3 sebanyak 4 responden, jenjang Pendidikan S1 sebanyak 46 responden dan jenjang Pendidikan S2 sebanyak 15 responden. Pengguna finance teknology produk Gopay dan Ovo paling banyak digunakan oleh jenjang Pendidikan S1 maka dapat disimpulkan bahwa orang/responden yang memakai finance teknology dengan produk Gopay dan Ovo adalah orang/responden yang cukup matang dan Pendidikan.

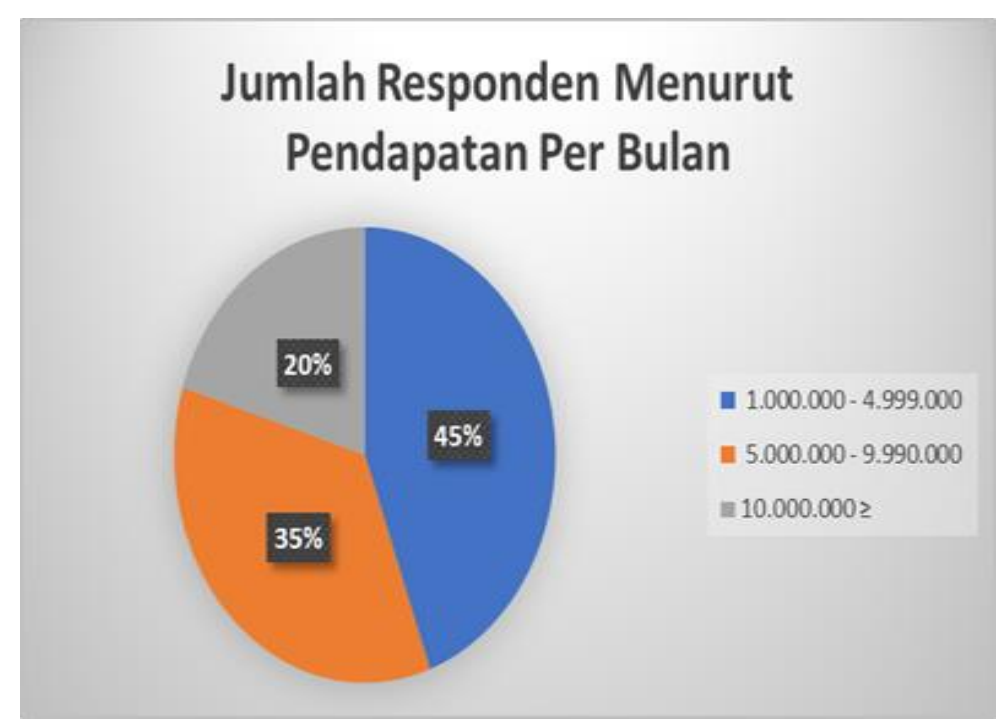

Grafik 4. Responden menurut Jumlah Pendapatan per bulan

Responden yang memiliki jumlah pendapatan sebanyak 1.000.000 - 4.999 .000 berjumlah 44 responden, responden yang memiliki pendapatan 5.000.000 - 9.990.000 sebnayak 35 responden dan ada sebanyak 20 responden memiliki pendapatan $10.000 .000 \geq$. Maka dapat disimpulkan dalam penelitian ini bahwa responden yang memiliki pendapatan dibawah 5.000.000 paling banyak menggunakan finance teknology. 


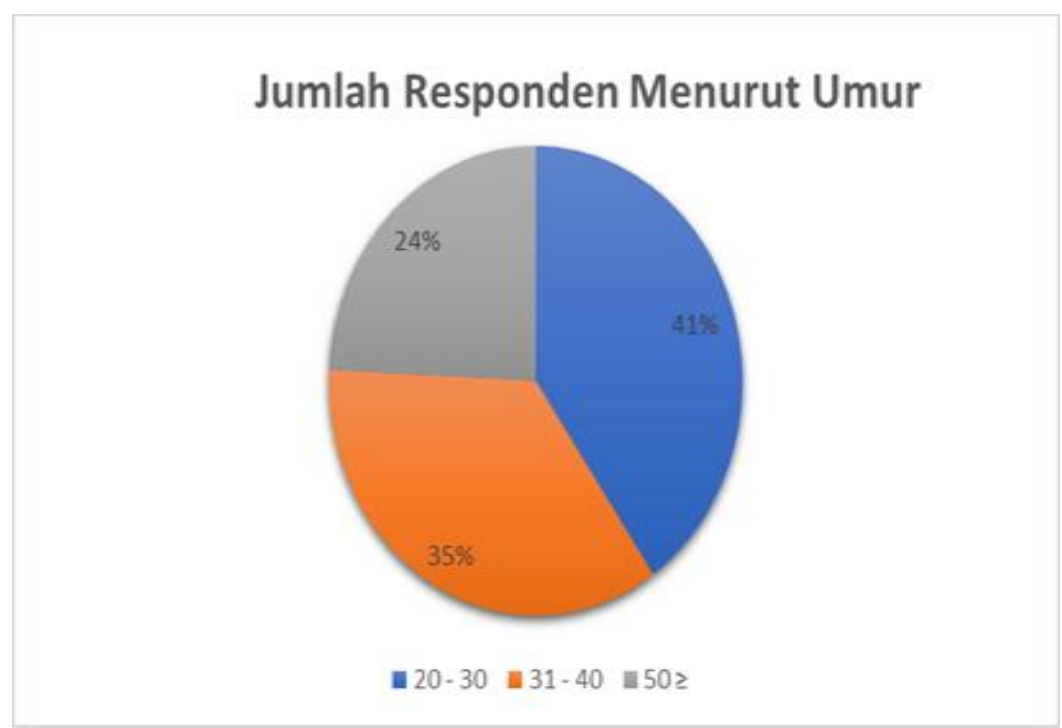

Grafik 5. Jumlah Responden menurut Umur

Juka dilihat hasil Grafik di atas jumlah responden menurut usia yang terdiri dari usia dari 20 tahun sampai 30 tahun berjumlah 40 responden, usia dari 31 tahun sampai - 40tahun berjumlah 35 dan usia dari diatas 50 tahun berjumlah 24. Dengan hasil itu maka bisa di simpulkan bahwa usia produktif mendominasi penggunaan financial teknology.

Di bawah ini merupakan deskripsi penyajian data berdasarkan jawaban dari kuesioner penelitian variabel Financial technology yang dirangkum dan ditabulasi dalam tabel frekuensi sebagai berikut:

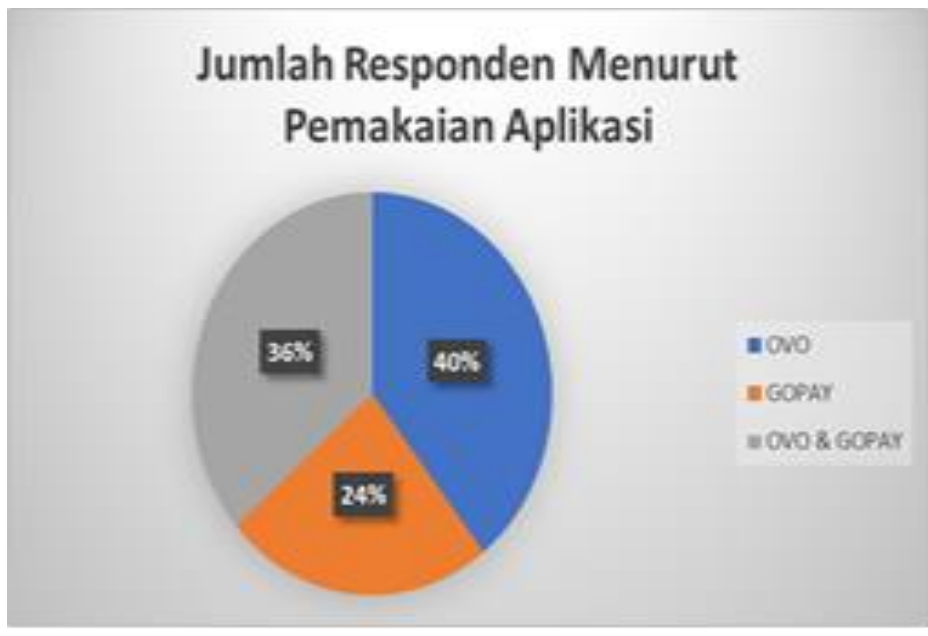

Grafik 6. Responden menurut Pemakaian Aplikasi

Tabel di atas menyimpulkan bahwa reponden yang memakai aplikasi OVO ada sebanyak 39 responden, aplikasi GOPAY sebanyak 24 responden dan pengguna aplikasi OVO \& GOPAY ada sebanyak 36 responden.

\section{PEMBAHASAN}

Pembahasan dalam penelitian ini akan dijabarkan melalui hipotesis dari penelitian berdasarkan analisis data yang sudah dilakukan sebelumnya. Untuk lebih jelasnya dapat dijelaskan sebagai berikut: Berdasarkan hasil penelitian faktor yang mempengaruhi penggunaan fintech dari sisi pengguna adalah usia, jenis kelamin, pekerjaan, pendapatan, tingkat pendidikan dari pengguna fintech. Dari 99 orang responden dalam penelitian ini mayoritas responden berjenis kelamin perempuan. Untuk kelompok usia mayoritas responden berada pada usia 19 tahun. Untuk pendapatan mayoritas responden memiliki pendapatan > 5.000.000. dalam pengisian dana dalam 1 bulan mayoritas responden melakukan http://ejournal.stiemj.ac.id/index.php/akuntansi 
pengisian 3 kali atau sebanyak 65 responden. Sehingga pengeluaran rutinitas responden dalam menggunakan fintech sebanyak 64 orang menyatakan sering dan yang percaya pada financial technology.

Financial technology sangat berperan dalam meningkatkan literasi keuangan di DKI Jakarta hal ini ditandai dengan responden memahami dengan baik tentang finansial teknologi OVO, mengetahui dengan pasti produk-produk dari OVO, merasa lebih dimudahkan dalam mengakses produk-produk keuangan dengan adanya OVO, responden juga merasa ada manfaat jika bertransaksi menggunakan produk OVO. Dalam hal penggunaan responden berniat untuk menggunakan produk OVO karena lebih praktis sehingga responden tertarik dengan adanya fintech sebagai inovasi baru dari industri keuangan. Disamping itu responden juga merancang keuangan untuk masa depan dan berharap akan terus menggunakan produk fintech yang dilakukan sebagai alat pembayaran dan akan terus berlanjut di masa yang akan datang. Sehingga dengan mengetahui dan menggunakan financial technology maka akan meningkatkan literasi keuangan generasi milenial, hal ini ditandai dengan responden sudah memahami tentang keuangan secara umum khusus tentang tabungan, produk fintech, mengikuti perkembangan perekonomian, mayoritas responden juga membuat list pengeluaran untuk bulanan karena mereka menyadari keuangan perlu direncanakan dengan baik sehinga mereka dapat membandingkan harga ketika membeli sesuatu barang suatua saat nanti, serta mengetahui barang yang akan dibeli berguna untuk kebutuhan mereka.

Para responden tidak serta merta langsung menggunakan fintech, tetapi beriringan dengan berkembangnya teknologi yang membuat para generasi milenial harus bisa menggunakan fintech. Sebelum menggunakan fintech pengguna haruslah mengetahui apa yang menjadi kendala setelah menggunakan fintech karena penggunaan diharapkan untuk jangka panjang. Selain itu, generasi milenial harus mempertimbangkan faktor - factor apa saja yang membuat mereka memilih aplikasi fintech sebelum menggunakan aplikasi tersebut. Faktor yang membuat responden menggunakan fintech dari sisi aplikasi yaitu:

a. Perkembangan teknologi

Generasi milenial harus beradaptasi dengan teknologi itu diperlukan agar generasi milenial dapat mengikuti alur perkembangan teknologi dan tidak ketinggalan akan perkembangan jaman

b. Minat konsumen

Konsumen semakin bergantung pada teknologi, yang membuat teknologi juga semakin berkembang pesat. Hampir setiap hari para konsumen tidak terlepas dari smartphone, dan membuat semua pekerjaan dilakukan pada smartphone seperti belanja, bahkan memesan makanan via aplikasi pada smartphone. Konsumen menginginkan kemudahan dalam bertransaksi dan kepraktisan. Semakin banyak minat konsumen terhadap teknologi, membuat para pelaku usaha harus menggunakan teknologi. Fintech menawarkan berbagai macam karakteristik untuk para penggunanya, sehingga memberikan kesan yang baik dan memudahkan kepada para pengguna layanan fintech. Kemudahan yang ditawarkan dari fintech membuat generasi millenial menerapkan fintech dalam bertransaksi.

c. Kenyamanan

OVO memudahkan para pelanggan bertransaksi menggunakan aplikasi OVO sehingga pelanggan tidak perlu melakukan pembayaran manual. 


\section{PENUTUP \\ Simpulan}

Berdasarkan hasil penelitian dan pembahasan tentang faktor yang mempengaruhi penggunaan aplikasi financial technology (fintech) dan dampaknya dalam meningkatkan literasi keuangan di DKI Jakarta, dapat disimpulkan faktor yang dapat mempengaruhi penggunaan aplikasi fintech dari sisi pengguna adalah usia, jenis kelamin, pekerjaan, pendapatan, tingkat pendidikan dari pengguna fintech sedangkan dari sisi aplikasi fintech adalah perkembangan teknologi dari aplikasi fintech, minat konsumen terhadap fitur dan produk yang ditawarkan oleh aplikasi fintech serta kenyamanan pengguna dalam menggunakan aplikasi fintech, adanya peranan Fintech dalam inklusi keuangan untuk meningkatkan literasi keuangan masyarakat di DKI Jakarta. Hal ini dapat dilihat bahwa generasi milenial sudah hampir merata dalam menggunakan aplikasi fintech yang dapat memberikan kemudahan untuk mengakses berbagai jenis layanan keuangan yang dibutuhkan dan penggunaan layanan Financial technology oleh pengguna ponsel pintar atau smartphone dapat menjadi jawaban dari upaya-upaya pemerintah yang membangun kebiasaan less-cash society. Sebab jumlah dari pengguna ponsel pintar atau handphone di Indonesia sudah sangat banyak. "Penetrasi ponsel pintar atau smartphone di Indonesia sudah melebihi penetrasi dari akun bank di Indonesia." Yang yang berdampak pada peningkatan Literasi Keuangan masyarakat di DKI Jakarta.

\section{Saran}

Saran bagi para pebisnis yang akan melakukan bisnis dibidang fintech dapat menjadi bahan pertimbangan menganai faktor- factor yang diuraikan diatas yang dapat mempengaruhi penggunaan aplikasi fintech dari sisi pengguna dan dari sisi aplikasi fintech. Pemerintah diharapkan mendukung para pebisnis startup terutama dibidang fintech secara pro aktif baik dari segi kebijakan dan program program yang strategis. Bagi peneliti selanjutnya dapat mencakup jangkauan wilayah penelitian yang lebih luas dan sampel yang lebih banyak guna menghasilkan kualitas penelitian yang lebih baik.

\section{REFERENSI}

Fauzie, S., \& S Istanto, L. (2014). Analisis Dampak Pembayaran Non Tunai Terhadap Jumlah Uang Beredar Di Indonesia. Jurnal Ekonomi Dan Keuangan, 2(10), 610-621.

Huston, S. J. (2010). Measuring Financial Literacy. Journal Of Consumer Affairs, 44(2), 296-316. Https://Doi.Org/10.1111/J.1745-6606.2010.01170.X

Luh Regita Eka Pratiwi, A. K. (2019). Pengaruh Literasi Keuangan Terhadap Financial Self- Efficacy Pada Usia Produktif Di Kabupaten Buleleng, Bali. Jurnal Mitra Manajemen, 2(4), 273-285. Http://E-Jurnalmitramanajemen.Com/Index.Php/Jmm/Article/View/125/69

Muhammad Saleh, Fatima Sari F, S. (2018). Pengaruh Literasi Keuangan Dan Kualitas Pembelajaran Keuangan Terhadap Penggunaan Fintech Mahasiswa Manajemen Dan Akuntansi Universitas Fajar. Jurnal Manajemen Dan Organisasi Review (Manor), 5(3), 2018.

Putu Adriani Prayustika, I Gede Iwan Suryadi, I Wayan Edi Arsawan, Dan I. M. W. (2020). Peran Financial technology Dalam Meningkatkan Literasi Keuangan Mahasiswa. Artificial Intelligence And The Law, 6(2), 31-48. Https://Doi.Org/10.4324/9780429344015-2

Situmorang, D., \& Hapsari, V. R. (2019). Faktor-Faktor Yang Mempengaruhi Perilaku Belajar Akuntansi Di Daerah 3t. Jurnal Akuntansi, Ekonomi Dan Manajemen Bisnis, 7(1), 77-84. Https://Doi.Org/10.30871/Jaemb.V7i1.1406

Situmorang, D. M., \& Ayustia, R. (2019). Model Pembangunan Daerah 3t: Studi Kasus Daerah Perbatasan Kabupaten Bengkayang. Mbia, 18(1), 49-64. Https://Doi.Org/10.33557/Mbia.V18i1.321fatmawati, M. N. R., \& Yuliana, I. (2019). Pengaruh Transaksi Non Tunai Terhadap Jumlah Uang Beredar Di Indonesia Tahun 2015- 2018 Dengan Inflasi Sebagai Variabel Moderasi. Ekspansi: Jurnal Ekonomi, Keuangan, Perbankan Dan Akuntansi, 11(2), 269-283. Https://Doi.Org/10.35313/Ekspansi.V11i2.1608

Fauzie, S., \& S Istanto, L. (2014). Analisis Dampak Pembayaran Non Tunai Terhadap Jumlah Uang Beredar Di Indonesia. Jurnal Ekonomi Dan Keuangan, 2(10), 610-621.

Herawati, N. T., Candiasa, I. M., Yadnyana, I. K., \& Suharsono, N. (2018). Pengaruh Kualitas Pembelajaran Keuangan Dan Literasi Keuangan Terhadap Financial Self Efficacy Mahasiswa 
Akuntansi. In Jpeka: Jurnal Pendidikan Ekonomi, Manajemen Dan Keuangan (Vol. 2, Issue 2, P. 115). Https://Doi.Org/10.26740/Jpeka.V2n2.P115-128

Prayustika, P. A., Suryadi, I. G. I., Arsawan, I. W. E., \& Widiantara., I. M. (2020). Peran Financial technology Dalam Meningkatkan Literasi Keuangan Mahasiswa. Artificial Intelligence And The Law, 6(2), 31-48. Https://Doi.Org/10.4324/9780429344015-2

Tiwu, M. I. H. (2020). Pengaruh Pandemic Covid 19 Terhadap Npl Bank Perkreditan Rakyat Di Indonesia. Jurnal Akuntansi: Transparansi Dan Akuntabilitas, 8(2), 79-87. 